\title{
Desafios contemporâneos em educação profissional: formação docente, linguagem e práticas pedagógicas
}

\author{
Contemporary challenges in professional education: teacher education, language and \\ pedagogical practices
}

\section{Desafíos contemporáneos en la educación profesional: Formación de profesores, lenguaje y prácticas pedagógicas}

\author{
Rosália Maria Netto Prados ${ }^{1}$ \\ Rodrigo Avella Ramirez ${ }^{2}$ \\ Cassia Regina Gasparin dos Santos Pereira ${ }^{3}$ \\ Juliana de Souza Lamas ${ }^{4}$
}

\section{Resumo}

Propõe-se um estudo da linguagem, discursos e práticas pedagógicas para uma reflexão sobre a formação docente em educação profissional frente aos desafios impostos pelo contexto contemporâneo. Os discursos educacionais, culturais e socioeconômicos subjazem às práticas pedagógicas na educação profissional. Este estudo fundamenta-se em conceitos teóricos de educação profissional, sobre saberes e formação do professor, além de concepções de linguagem e discurso, no âmbito da comunicação docente. $O$ desenvolvimento desta pesquisa teve como objetivos, discutir a formação de docentes em educação profissional; estudar a linguagem e práticas educacionais, e respectivos discursos, para se refletir sobre as novas tecnologias e emergências no processo de ensino em educação profissional no contexto de isolamento social imposto em função da pandemia causada pela Covid-19. Trata de uma pesquisa de abordagem qualitativa, a partir de questões suscitadas, ao longo do processo de ensino e aprendizagem, em uma disciplina eletiva de um programa de mestrado profissional. A metodologia constituiu-se de uma pesquisa descritiva e de um estudo da comunicação, tecnologias e do discurso manifestado nas práticas pedagógicas em educação profissional. Verifica-se que a experiência docente reflete discursos político-educacionais e pedagógicos em educação profissional e constitui o processo de formação do professor.

\footnotetext{
${ }^{1}$ Professora doutora, pesquisadora do Programa de Pós-Graduação no programa de mestrado em Gestão e Desenvolvimento da Educação Profissional, do Centro Estadual de Educação Tecnológica Paula Souza (CEETEPS). Área de Educação Profissional e Tecnológica. E-mail: rosalia.prados@gmail.com ORCID: http://orcid.org/0000-0003-2138-8422

${ }^{2}$ Doutor em Educação pela Universidade Mackenzie; professor pesquisador do programa de mestrado em Gestão e Desenvolvimento da Educação Profissional do Centro Estadual de Educação Tecnológica Paula Souza (CEETEPS). E-mail: roram1000@ hotmail.com ORCID: http://orcid.org/0000-0001-8468-2851

${ }^{3}$ Mestranda no programa de mestrado em Gestão e Desenvolvimento da Educação Profissional, do centro estadual de educação tecnológica Paula Souza. E-mail: cassiagasparinadv@gmail.com ORCID: http://orcid.org/0000-0003-0134-7201

${ }^{4}$ Mestranda do programa de mestrado em Gestão e Desenvolvimento da Educação Profissional do Centro Estadual de Educação Tecnológica Paula Souza (CEETEPS). E-mail: julianaslamas@gmail.com ORCID: http://orcid.org/0000-0001-5431-5153
} 
Palavras-Chave: Formação Docente; Linguagem e Práticas; Pandemia; Novas Tecnologias.

\begin{abstract}
We propose a study of the pedagogical language, discourses and practices for a reflection on teacher education in professional education facing the challenges imposed by the contemporary context. The educational, cultural and socioeconomic discourses underlie pedagogical practices in professional education. This study is based on theoretical concepts of professional education, on knowledge and teacher education, in addition to concepts of language and discourse, in the context of teacher communication. The development of this research aimed to discuss the training of teachers in professional education; study the language and educational practices, and respective discourses, to reflect on new technologies and emergencies in the teaching process in professional education in the context of social isolation imposed by the pandemic caused by Covid-19. It is a research with a qualitative approach, based on questions raised during the teaching and learning process, in an elective course content of a professional master's program. The methodology consisted of a descriptive research and a study of communication, technologies and the discourse manifested in pedagogical practices in professional education. We appear that the teaching experience reflects political-educational and pedagogical discourses in professional education and constitutes the teacher training process.
\end{abstract}

Key words: Teacher Education; Language and Practices; Pandemic; New technologies.

\title{
Resumen
}

Propone un estudio del lenguaje, los discursos y las prácticas pedagógicas para una reflexión sobre la formación del profesorado en la formación profesional frente a los desafíos que impone el contexto contemporáneo. Los discursos educativos, culturales y socioeconómicos subyacen a las prácticas pedagógicas en la educación profesional. Este estudio se basa en conceptos teóricos de la formación profesional, en el conocimiento y la formación docente, además de conceptos de lenguaje y discurso, en el contexto de la comunicación docente. El desarrollo de esta investigación tuvo como objetivo discutir la formación del profesorado en la formación profesional; Estudiar el lenguaje y las prácticas educativas, y los discursos respectivos, para reflexionar sobre las nuevas tecnologías y emergencias en el proceso de enseñanza en la educación profesional en el contexto de aislamiento social impuesto por la pandemia provocada por Covid-19. Se trata de una investigación con enfoque cualitativo, basada en cuestiones planteadas durante el proceso de enseñanza y aprendizaje, en una asignatura optativa de un programa de maestría profesional. La metodología consistió en una investigación descriptiva y un estudio de la comunicación, las tecnologías y el discurso manifestado en las prácticas pedagógicas en la educación profesional. Parece que la experiencia docente refleja los discursos político-educativos y pedagógicos en la formación profesional y constituye el proceso de formación docente.

Palabras clave: Formación de profesores; Lenguaje y prácticas; Pandemia; Nuevas tecnologías. 


\section{Introdução}

No atual contexto sociocultural e econômico, em que se insere a educação profissional e tecnológica, é cada vez mais relevante apreender os discursos político-educacionais e pedagógicos manifestados nas práticas docentes e se refletir sobre as linguagens e comunicação. Em um processo de formação pedagógica do professor que atua em educação profissional, é pertinente considerar que o sujeito contemporâneo é formado em uma cultura digital, dada a necessidade atual de interação por meio de diferentes linguagens na comunicação e nos processos educacionais.

A educação profissional, segundo esse pressuposto, apresenta-se na sociedade contemporânea, enquanto experiência tecnológica para propor estratégias de interação social ou sociabilidade para atender às exigências sociais e econômicas. Considera-se que, em um programa de mestrado profissional em Gestão e Desenvolvimento da Educação Profissional, justificam-se estudos sobre concepções da linguagem, tecnologias e comunicação docente, além da noção de discurso e formação do sujeito em educação profissional e tecnológica.

A formação do professor na educação profissional se dá por diferentes discursos educacionais e pedagógicos e pela produção de sentidos manifestados por meio de novas linguagens e tecnologias. Desse modo, definiu-se a proposta de uma disciplina eletiva sobre Linguagem e Práticas em Educação Profissional, de acordo com o desafio educacional de se (re)pensar sobre os efeitos discursivos que se atualizam constantemente frente às novas tecnologias e à experiência humana da comunicação na atualidade.

Este artigo se baseia em discussões vivenciadas pelos alunos que cursaram essa disciplina de Linguagem e Práticas em Educação Profissional, em um programa de mestrado profissional em Gestão e Desenvolvimento da Educação Profissional, de uma instituição pública estadual de educação profissional e tecnológica de São Paulo. O percurso metodológico que orientou este estudo foi de natureza descritiva, a partir de uma pesquisa de abordagem qualitativa, de acordo com a observação e a análise de apresentação de seminários de leituras temáticas sobre educação profissional (PETEROSSI, 2014); educomunicação (KAPLÚN, 2014); discurso (MAINGUENEAU, 2008; FONTANILLE, 2008); formação do professor (GATTI et al, 2019) e tecnologias (SOARES, 2006), além de anotações dos autores sobre questionamentos e discussões suscitados em sala de aula. 
Como objetivos, propõe-se discutir a formação de docentes em educação profissional; estudar a linguagem, a comunicação e as práticas educacionais, bem como seus respectivos discursos, para se refletir sobre as novas tecnologias e emergências no processo de ensino em educação profissional no contexto de isolamento social imposto em função da pandemia causada pela Covid-19.

É pertinente considerar a educação profissional no novo cenário socioeconômico brasileiro, inserida em uma cultura digital e, consequentemente, seus desafios. A inovação e a melhoria da formação profissional, em relação às tecnologias de informação, são necessidades básicas das empresas contemporâneas.

Segundo Pais (2007), o homem está inserido em uma comunidade sociocultural, é um ser social, cultural e histórico. Identifica-se com saberes e valores compartilhados em um determinado grupo, por uma visão de mundo, por um imaginário coletivo. De acordo com o autor, esses valores e saberes habilitam o sujeito ao convívio social e conferem aos membros de um grupo a sua identidade cultural, a sua memória social, a consciência da sua pertinência ao grupo e de sua continuidade no tempo. E, quanto à discussão sobre formação docente na educação profissional, bem como as exigências da sociedade cultural e socioeconômica contemporânea, justificam-se, portanto, essas concepções sobre linguagem, tecnologias, comunicação e educação.

No desenvolvimento deste trabalho, delineiam-se três etapas: a primeira, Formação do professor na educação profissional, apresenta algumas discussões conceituais, quanto saberes e formação docente, debatidas no programa de mestrado profissional; a segunda, Discursos contemporâneos e a educação, trata de reflexões acerca do discurso educacional e exigências contemporâneas; e a terceira, Comunicação docente, novas tecnologias e práticas em educação profissional, em que se descrevem os desafios do contexto contemporâneo, frente às exigências impostas pelo isolamento social, em função da pandemia causada pela Covid19, além de discussões sobre a comunicação, educação e linguagem, que fundamentam as práticas pedagógicas em educação profissional.

\section{Formação do professor na educação profissional}

A disciplina eletiva "Linguagem e Práticas em Educação Profissional e Tecnológica" foi oferecida em 2020, no programa de mestrado em Gestão e Desenvolvimento da Educação 


\section{OO DEVIR EDUCAÇÃO}

ISSN: 2526-849X

Profissional, de uma instituição pública estadual de educação profissional e tecnológica de São Paulo, de modo remoto, no período de isolamento social, imposto em quase todo o planeta, devido à pandemia da Covid-19. Essa disciplina traz em sua ementa as bases do estudo de linguagem, comunicação e educação, como o estudo dos signos, mídias e mediação escolar, além do foco em comunicação nos processos de ensino e aprendizagem em educação profissional e das tecnologias e ambientes de aprendizagem. Teve como objetivos, estudar a linguagem que permeia a educação profissional e respectivos discursos político-educacionais e político-pedagógicos; estudar a comunicação pedagógica; e descrever práticas educacionais, e seus discursos subjacentes, para se entender as exigências do mundo do trabalho e do ensino em educação profissional no atual contexto. Portanto, foi apresentada uma base teórica sobre Linguagem, Comunicação e Análise do Discurso, estudos contemporâneos de Educomunicação, Educação e Tecnologias.

Segundo Gariglio e Burnier (2012), há uma restrita produção científica sobre a formação do docente de educação profissional. E existe uma perspectiva reducionista nessa modalidade educacional, de que para ser professor de disciplinas, ou áreas tecnológicas, o conhecimento dos conteúdos se sobrepõe à formação pedagógica.

Há uma desarticulação entre a educação regular e a rede de formação profissional, de acordo com Peterossi (2014), uma vez que, inicialmente, a educação profissional foi organizada pela própria indústria, pelo conhecido Sistema $S^{5}$. Desse modo, as instituições de formação profissional desenvolveram uma mentalidade decorrente desse processo educacional, nitidamente empresarial, além de incorporarem procedimentos eminentemente técnicos em sua estrutura e organização.

Nos estudos sobre a formação de professores, para Gariglio e Burnier (2012), discutese que os saberes docentes não podem ser reduzidos somente ao conhecimento dos conteúdos das disciplinas. No processo de ensino, é necessário muito mais do que simplesmente o conhecimento do conteúdo, mesmo que esse conhecimento seja fundamental.

[...] a forma como vem ocorrendo a formação pedagógica dos professores da EP no país, como algo especial, emergencial, sem integralidade própria, não

\footnotetext{
${ }^{5} \mathrm{O}$ Sistema S constitui-se de instituições administradas de forma independente por federações e confederações empresariais dos principais setores da economia. "Apesar de prestarem serviços públicos, essas entidades não estão ligadas a nenhuma das esferas de governo. Estão no grupo, tanto instituições voltadas à educação profissional [SENAI, SENAC], quanto outras voltadas a prestação de serviços ligados ao bem-estar social [SESC, SESI]" (BRASIL, 2020).
} 
contribuiu para a construção de referenciais e diretrizes mais claras sobre um modelo de formação inicial e continuada que respondesse às especificidades da atuação profissional desses docentes (GARIGLIO; BURNIER, 2012, p. 216).

Considerem-se as inovações tecnológicas que, no contexto contemporâneo com novos formatos de empresas e novas formas de gestão, como as indústrias 4.0, novos programas de gestão comercial e empresarial que exigem mudanças no perfil do trabalho e do emprego. Essas novas exigências, além do contexto histórico e social da educação profissional e tecnológica, constituem um campo de tensões discursivas que suscitam discussões sobre a comunicação docente e o trabalho pedagógico.

Embora os professores que atuam na esfera da educação profissional apresentem uma experiência na área prática da sua profissão de formação, no momento em que se inserem em uma instituição de ensino profissional, muitos se apoiam em modelos pedagógicos conhecidos de outros professores, ou mesmo de suas experiências (TARDIFF, 2014). É possível se observar que profissionais de mercado que têm muita experiência para compartilharem, não dominam saberes da docência.

Para Gatti (et al, 2019), a história da educação no Brasil revela alguns traços persistentes e problemáticos, como a dificuldade em se ter professores habilitados para cobrir as demandas da população escolarizável, ou ainda, dificuldade para oferecer uma formação sólida, além da falta de recursos suficientes para dar a eles condições de trabalho e remuneração adequada. E, ainda de acordo com Gatti (et al, 2019), a história da formação de professores no Brasil mostra uma descaracterização progressiva desse processo que se reflete no contexto da educação profissional.

Assim, para o desenvolvimento de uma discussão sobre a linguagens, tecnologias e comunicação nos processos educativos em educação profissional, adotou-se uma perspectiva de estudo do discurso, que trata das relações de linguagem, como a interdiscursividade ${ }^{6}$, da cultura contemporânea, das exigências do mundo do trabalho e da educação. Além disso, foi possível ampliar o debate sobre as relações inter, multi e transdisciplinares ${ }^{7}$ das linguagens e tecnologias, bem como, de seus vínculos na sociedade, a partir de tensões e valores socioculturais e de suas manifestações no campo educacional.

\footnotetext{
${ }^{6}$ Relações entre discursos, atualização de um discurso para uma situação nova (MAINGUENEAU, 2008).

${ }^{7}$ Relações inter, multi e transdisciplinares, o discurso apresenta-se como dimensão atualizadora de resultantes parciais, a fim de fomentar intercâmbios de ações interdisciplinares na produção ativa do conhecimento humano (BASSIT, 2010).
} 
Nas práticas sociais, em situações de comunicação, são produzidos vários discursos sobre cidadania, trabalho, igualdade de direitos, ou vontade política. De acordo com Pais (2007), um único e mesmo discurso pode pertencer, simultaneamente, a mais de um universo de discurso, de modo que se caracteriza uma interdiscursividade, por exemplo, um discurso publicitário pode estar inserido num universo de discurso feminino, político ou educacional.

Ao se adotar essa perspectiva de análise do discurso, é possível se observar que as arbitrariedades, formas cristalizadas ou convencionais que nele se apresentam não são unicamente signos, mas processos de significação. Segundo Fontanille (2008), uma das propriedades mais interessantes do discurso é a esquematização das representações e experiências humanas. Assim, o estudo do discurso impõe-se no lugar do estudo dos signos propriamente ditos.

De modo que, nessa discussão, considera-se que o discurso é um processo de produção de sentido, gerado a partir de textos produzidos em uma determinada situação histórica e contexto social, com a finalidade de se criar certos sentidos e de atingir determinados interlocutores. É importante considerar que todo discurso reflete uma ideologia, ou seja, uma forma particular de se ver e de se pensar o mundo (PRADOS et al, 2020).

Todo discurso, de acordo com Prados, Ramirez e Fernandez (2020), pode fazer parte ou ser citado em novos discursos, além de formar parte de uma classe de textos, ou de um corpus textual de uma cultura. Assim, pode-se dizer que todo discurso é parte de uma história de discursos, de modo que se caracterizam, assim, a interdiscursividade ou ideologia, e a intertextualidade.

No desenvolvimento do programa da disciplina proposta, de que se trata neste trabalho, em encontros semanais de quatro horas, houve uma distribuição de temas que abordam a complexidade da formação e do trabalho docente em educação profissional, cotidiano da/na escola e da/na sociedade. Foi oportuno perceber que se vive e se produz conhecimento na realidade cotidiana do exercício profissional e da sala de aula, a fim de se refletir sobre o saber vivenciado e compartilhado em um processo contínuo de formação docente.

\section{Discursos contemporâneos e a educação}


Neste estudo que se propôs para o desenvolvimento da disciplina de Linguagem e Práticas em Educação Profissional, consideraram-se, primeiramente, os saberes docentes, diante de emergências contemporâneas sociais, econômicas, tecnológicas e culturais, de acordo com um conjunto de orientações para o acesso a novas ferramentas de informação e comunicação disponíveis, bem como discussões sobre comunicação docente e novas metodologias. Além de um outro ponto, que diz respeito à formação do professor, quanto ao exercício docente e ao uso dessas novas tecnologias, uma vez que esse, via de regra, não foi preparado academicamente, no que se refere às tecnologias de informação e comunicação contemporâneas, bem como sua integração com a realidade para além das salas de aula.

Para isso foi pertinente adotar-se a concepção de discurso, de acordo com a Semiótica de linha francesa, segundo a qual o discurso é visto como resultado de uma expressão humana que produz representações e experiências. Trata de uma tendência teórica de análise semiótica, que se baseia na teoria da linguagem, pois a existência das coisas somente faz sentido por meio da produção de um discurso que lhes atribui significados, ou seja, o discurso produz sentido (PRADOS; BONINI, 2017).

Em sua metodologia de análise, segundo Prados e Bonini (2017), essa perspectiva semiótica não trata somente do signo, mas da significação, que pode ser entendida como processos de produção ou de interpretação de sentidos, que se armazenam na memória, recuperam-se e se transformam permanentemente. Assim a significação é tratada como um percurso, no qual o sentido é gerado, ou seja, aquele em que se dá a atualização de elementos disponíveis para qualquer produção discursiva, em quaisquer linguagens verbal, não-verbal ou sincréticas. Foram pertinentes, para essa discussão, as contribuições dos estudos do discurso educacional, de acordo com essa perspectiva semiótica discursiva, de Greimas (2001), que possibilita a reconstrução do processo discursivo das práticas educacionais, para se considerarem os discursos subjacentes à educação profissional.

Nas práticas sociais e educacionais, manifestam-se, portanto, os discursos que refletem os sistemas de valores de uma sociedade. A fim de que se possa pensar a educação profissional contemporânea, os anseios e as expectativas dos sujeitos, é necessário se pensar o discurso educacional, como um dos discursos constituintes, dotado de maior autonomia e que confere [...] "sentido aos atos da coletividade, aquilo para além dos quais não há mais do que o indizível. Zonas de falar, entre outras, e falas que se pretendem acima de qualquer outra" (MAINGUENEAU, 2008, p. 138). 
Segundo Maingueneau (2008), o discurso educacional se organiza em torno de textos de referência, ligados a instituições que garantem sua necessidade de interpretação e de autorização. Entende-se que o discurso educacional sustenta-se em sistemas de valores que, por sua vez, reproduzem, não só os discursos políticos-educacionais ou pedagógicos, mas também outros tantos sobre cidadania, ética, vontade política, até os discursos políticosalariais, de classe etc.

Em relação ao campo discursivo, a educação profissional, para Prados (2020), apresenta especificidades de discursos, como o das exigências do mundo de trabalho, do sistema administrativo e, também, do sistema político. É recorrente o discurso de que a educação profissional trata de um sistema de renovação da potencialidade humana para a atualização constante e necessária no contexto contemporâneo de desenvolvimento acelerado de novas tecnologias e de novos paradigmas no mundo do trabalho.

Evidenciam-se, assim, no trabalho docente, essas relações discursivas e interdisciplinares de linguagens e tecnologias, bem como de seus vínculos na sociedade e de suas manifestações no campo educacional. Segundo Prados, Ramirez e Fernandez (2020), a formação em educação profissional se dá por variados processos de produção de sentidos, que se manifestam por meio de linguagens e diferentes processos semióticos, como o verbal, o não-verbal, ou sincrético (o visual, o gestual etc.).

Neste estudo sobre a comunicação docente em educação profissional, a partir de leituras sobre linguagens, tecnologias, discurso, comunicação e educação, foram relevantes as contribuições dos estudos contemporâneos de Educomunicação. Tais discussões são pertinentes no atual contexto, já que o enfoque da comunicação na educação não deve se limitar apenas ao estudo da mídia, das ferramentas, das tecnologias que, segundo Kaplún (2014), é uma redução empobrecedora, pois para esse autor, a Educomunicação compreende a comunicação em processos educativos em que se busca um resultado formativo. É pertinente, na contemporaneidade, o estudo sobre essa perspectiva da comunicação nas práticas pedagógicas em educação profissional, uma vez que a ênfase no processo significa ver a educação como um processo permanente.

Para essa discussão sobre o campo da Educomunicação, que é uma perspectiva interdisciplinar, foram considerados aspectos do discurso, como os processos identificatórios, pois, segundo Coracini (2003), é possível interpretar pontos de identificação que aparecem pela linguagem, ou vozes constitutivas da subjetividade. A complexidade da identidade é 


\section{OO DEVIR EDUCAÇÃO}

ISSN: 2526-849X

marcada pelo outro, por aqueles do convívio diário, da cultura local e de outras que causam em nós, ressignificações, outras identificações pela linguagem (CORACINI, 2003).

E, quando se introduz o aspecto dinâmico das tecnologias emergentes na educação e na sociedade, a fim de se acompanhar as modificações das coisas no mundo contemporâneo, pode-se relacionar as consequências de tais mudanças no processo educacional e, assim, são pertinentes as contribuições da Educomunicação, uma vez que novas experiências têm provocado mudanças significativas na constituição e formação do sujeito contemporâneo e, consequentemente, no processo formativo do professor e práticas docentes em educação profissional.

\section{Comunicação docente, novas tecnologias e práticas em educação profissional}

Em decorrência do surgimento de um novo vírus, o SARS-CoV-2, ou Covid-19, configurou-se a pandemia, em 2020, que atingiu a todos e exigiram-se novas práticas em diferentes contextos, no mundo do trabalho em várias e diferentes funções. E, na educação, o desafio foi a adoção das novas tecnologias, como o uso das mídias digitais, ferramentas tecnológicas, softwares, o que exigiu de todos, docentes e discentes, a quebra de paradigmas tradicionais e a urgência de se repensarem novas práticas docentes.

Na educação profissional, espera-se que, segundo Peterossi e Menino (2017), sejam reconhecidas as tendências atuais, ou futuras, e como elas podem impactar a prática educacional, de maneira que seja capaz de educar para a tecnologia, para a inovação, para o desenvolvimento sustentável e para o trabalho. Assim, é necessário que o educador esteja preparado para responder às demandas da sociedade, de mercado e do poder público.

Diante desse contexto, em que as práticas pedagógicas e a comunicação docente apresentam novos desenhos, mesmo com o gradual retorno presencial nas escolas, evidenciase a necessidade da inserção das tecnologias digitais no processo educacional. Revelaram-se problemas quanto ao conhecimento das mídias digitais e o uso das tecnologias de informação pelo professor, que até então se reduziam ao operacional (ALVAREZ; PRADOS, 2020).

Segundo Aparici e Osuna (2014), a educomunicação encontra-se em um contexto de convergência das tecnologias e linguagens midiáticas. E destacam a forma como foram inseridas as ferramentas tecnológicas dentro dos espaços educacionais, além de considerações 


\section{OO DEVIR EDUCAÇÃO}

ISSN: 2526-849X

sobre o modo como toda a infraestrutura das Tecnologias de Informação e Comunicação (TIC) é usada nas salas de aula de maneira tecnicista. De acordo com esses autores, essa prática desconsiderou o uso da ferramenta como objeto de estudo e construção do conhecimento.

Discutiu-se sobre o contex to do isolamento social, em função da pandemia, em que os professores se viram obrigados a questionarem suas práticas. Em educação profissional, não se é possível desvincular a comunicação pedagógica do contexto socioeconômico, cultural e tecnológico, quanto às demandas do trabalho e à necessidade de interação por meio das novas tecnologias. E, segundo Aparici e Osuna (2014), o professor precisa ter competência para acessar a informação, mas ao mesmo tempo deve ser criador de conteúdo virtual de modo crítico.

Para Soares (2006), caracterizam-se novos processos comunicacionais e cognitivos, advindos de um contexto constituído pelo ciberespaço, em que se questionam a educação formal, a sala de aula e a formação educacional. Evidencia-se uma conexão de saberes, em decorrência dessa hipertextualidade contemporânea. Nesse contexto, a existência do espaço é feita de muitas falas, conhecimento, construção coletiva e interpretações partilhadas.

Segundo Moura (2017), aprender a aprender na era digital significa ter um papel ativo na própria aprendizagem, saber procurar respostas para as dúvidas, saber acessar a fontes de informação para extrair dados relevantes, confiáveis e pertinentes, além de saber trabalhar colaborativamente e ter espírito crítico, a fim de encontrar soluções para os problemas. Assim as estratégias pedagógicas deveriam possibilitar o desenvolvimento de todas essas competências, para se garantir um elo educativo entre todas as atividades, como um todo integrado e contínuo, a fim de proporcionar qualquer avaliação.

Supõe-se que o ato de aprender possa ocorrer em todas as partes, como na sala de aula, ou no corredor na escola, ou ainda, em casa, em todos os locais onde se possam gerar situações de aprendizagem. Para Moura (2017), todo o alcance das teorias de aprendizagem existentes ainda está por se completar, frente ao potencial dos ambientes sociais e de aprendizagem conectados.

Aprender na era da informação e do conhecimento, segundo Moura (2017), impõe desafios. Para a autora, seriam essas teorias suficientes para atender aos princípios da aprendizagem e explicar os diferentes processos de aprendizagem em uma sociedade altamente tecnológica e conectada? Há teorias contemporâneas que tentam explicar a 


\section{OO DEVIR EDUCAÇÃO}

ISSN: 2526-849X

aprendizagem na sociedade do conhecimento na era digital e Moura (2017) cita, dentre elas, o conectivismo e a aprendizagem ubíqua.

O conectivismo apresenta-se como uma teoria para essa era digital e, segundo Moura (2017), supera as anteriores, segundo a natureza com que se produz o conhecimento em ambientes tecnológicos conectados e se baseia na importância de se gerar conexões e redes para criar padrões de informação. Segundo essa teoria, destaca-se a importância da formação de competências críticas, como a de distinguir uma informação relevante da que não é, além do reconhecimento de quando uma informação altera o seu contexto e a conexão de padrões. Nesse caso, o professor ensina o aluno a construir sua rede de conhecimentos, bem como aproveitar as oportunidades de aprendizagem, na geração de novas conexões.

Quanto à aprendizagem ubíqua, Moura (2017) destaca que qualquer pessoa pode aprender em qualquer momento, ou lugar, independentemente, de ser um processo educacional formal ou não. As novas tecnologias móveis são a base desse processo, que se baseia na necessidade de se construir um conhecimento colaborativo, critica o tecnicismo da aprendizagem, além de se reforçar uma pedagogia transformada e transformadora em um ambiente virtual de aprendizagem.

Essas abordagens teóricas, para Moura (2017), focalizam os alunos no centro da aprendizagem, que pode ocorrer em diferentes contextos sociais. Assim, a elaboração e reelaboração de conceitos não se realizam somente no plano individual, já que a colaboração torna possível que outros possam contribuir para a aprendizagem de todo o grupo. As atividades colaborativas permitem que todo o grupo possa comparar, validar, adaptar ou avaliar suas próprias conclusões. Em um ambiente de colaboração, o aluno pode participar ativamente para a resolução de problemas com os pares. E o conhecimento se dá por meio de um processo dinâmico decorrente de diferentes reestruturações cognitivas e não somente pela simples adição de informação.

Uma parte significativa de professores não domina as teorias que fundamentam suas práticas pedagógicas, muitos deles nem se veem como mediadores de um processo de ensino e aprendizagem, no entanto são bons profissionais de mercado que atuam em diferentes cursos de formação profissional (PETEROSSI; MENINO, 2017). Outros professores que lecionam em diferentes instituições, como muitas de ensino superior, ou mesmo de ensino técnico ou tecnológico da rede particular, também não tiveram uma formação específica 
pedagógica que os capacitasse para o ensino, pois muitos não são licenciados, são profissionais de mercado.

Além desses problemas, quanto à atividade docente, no que se refere à educação profissional, no contexto do isolamento social e da imposição do ensino remoto em função da pandemia, os professores viram-se diante de novos desafios, no que se refere à construção do conhecimento e novas metodologias de ensino. A relação tempo/espaço/realidade foi problematizada frente às adaptações de suas práticas. Discutiu-se sobre o ensino remoto, que se diferencia do ensino a distância assíncrono.

Para Aparici e Osuna (2014), em um tempo marcado pela interatividade, participação e colaboração observa-se uma desigualdade que promove 'infoexclusão', que trata de um fenômeno em que se diferencia o uso apenas operacional da tecnologia do seu uso proficiente. Caracteriza-se uma grande lacuna entre o que se trata dentro da escola sobre tecnologias e o que se vive fora dela.

Ao se analisar essa problematização da educação que se caracterizou nesse contexto da pandemia, verifica-se que foi ressignificado o discurso educacional, voltado ao professor de educação profissional, que pode ser descrito a partir das seguintes modalidades discursivas, segundo Prados e Bonini (2017), um poder-fazer-querer, para se adquirir um poder-saberfazer (competência).

De acordo com essa metodologia de análise discursiva, na produção da significação desse discurso apreendido pelos professores ao se depararem com a emergência do ensino remoto síncrono, apresentou-se uma necessidade, que pode ser descrita por um poder-fazerquerer que, por sua vez, instaurou um sujeito (professor) de um querer e produziu um sujeito (professor) que precisa adquirir competência para ser um sujeito de um saber e de um dever.

Ao se retomarem os discursos que constituem o professor, diante do contexto educacional de 2020, foi possível se refletir, também, sobre o que é ser alfabetizado em uma cultura digital, em que estar conectado à rede não é o suficiente. É preciso desenvolver competências que proporcionem aos indivíduos compreender e dominar a tecnologia, realizando interpretações críticas das diversas (e incontáveis) fontes de informações.

Foram pertinentes, também, as considerações sobre o contexto digital em que se vive e a relevância de se desenvolver um pensamento crítico sobre os limites das informações que são interiorizadas. Nesse contexto, segundo Aparici e Ozuna (2014), é um desafio 
desenvolver as capacidades listadas para uma efetiva alfabetização digital, visto que, ainda há resistência no sistema educativo, quanto ao uso dos ambientes virtuais.

Segundo Gomez (2014), as habilidades específicas para o produto como o trabalho, registros, conhecimentos e para o intercâmbio requerem esforços educativos, pois somente "ser" público, diante das telas não garante resultados esperados. Em verdade a interconectividade é um fenômeno que mantém os jovens sempre conectados e a várias telas para produzir novos significados. De acordo com Gomez (2014), essa seria a nova forma, ou a forma privilegiada de estar e ser público, saliente-se que essa habilidade não é nata e nem automática. Há, portanto, a necessidade de destacarem esforços educativos para a comunicação.

Diante desse cenário contemporâneo, essas ideais repercutem em toda a produção cultural e registre-se também na educação formal. Assim a educação hoje terá que continuar a enfatizar a criticidade ou o pensamento, porém na produção e na emissão, diante de um desafio da educomunicação, que contribui para estimular a criatividade e habilidades necessárias para o desenvolvimento das várias competências como explorar, argumentar e dialogar, bem como a produção convergente para produtos coletivos, éticos e solidários.

A educação voltada à formação de um público participativo, crítico, diante e a partir de diferentes meios de comunicação e de seus conteúdos, segundo Gomez (2014), parece ser uma utopia possível, a partir de um novo público, que seja receptor e produtor ao mesmo tempo. Todavia, para Gomez (2014), ao mesmo tempo que parece possível, demanda, ainda, um longo processo com desafios educativos e comunicativos mais complexos. Para tanto exige-se consenso em novos motivos para educar e novas abordagens pedagógicas, novos estilos comunicativos, diferentes habilidades a serem desenvolvidas tanto para os educadores como o público contemporâneo, além de definição de políticas públicas e a implementação de estratégias socioculturais e políticas.

Ao se discutirem práticas pedagógicas e a comunicação docente, diante dos desafios impostos no contexto vivido em 2020 e que persiste atualmente, considera-se relevante, o que Gomez (2014) apresenta como 'a condição comunicacional', ou seja, uma convergência, em que um público receptivo e receptor transforma-se em um público, essencialmente produtor e emissor, a fim de se permitir que os participantes envolvidos, mediados pelas telas, desconstruam e reinterpretem. Dessa forma são possíveis as várias intervenções pedagógicas, diálogos e geração de conhecimento.

Revista Devir Educação, Lavras-MG. Edição Especial, p.53-70, Set./2021. 


\section{OO DEVIR EDUCAÇÃO}

ISSN: 2526-849X

Para Gomez (2014), no ecossistema comunicativo sempre se está em condições de educar-se, de se aprender, de se explorar criativamente as tecnologias contemporâneas. Assim como o ensaiar, o errar e o descobrir, para se deixar o paradigma da imitação, memorização, repetição ou da cópia de modelos.

O aprendizado pode acontecer de maneira formal ou informal, mas, segundo Gomez (2014), é muito mais do que ensinamentos e nesse momento, transita-se de uma sociedade com sistema educativo para uma sociedade da educação. E cabe à educação aprofundar a problematização dos conhecimentos entre os usuários, para afinar, situar, completar ou reorganizar os aprendizados dos educandos com as telas.

Para Gomez (2014), as novas tecnologias (telas), como instrumento, os canais e linguagens não só garantem uma mudança cultural, mas um produto de qualidade diferente com a interação das telas. Ao longo do tempo, haverá uma identidade perdurável e flexível para ser reproduzida, modificada, trocada ou negociada, já que a interação com as telas, de certo modo, garante a subsistência no mundo cultural contemporâneo.

\section{Considerações finais}

O estudo da linguagem e práticas discursivas entre sujeitos no processo educacional, por meio da disciplina Linguagem e Práticas em Educação Profissional, possibilitou a percepção de que se vive e se produz conhecimento na realidade cotidiana do exercício profissional da docência, além de se refletir sobre o saber vivenciado e compartilhado em um processo contínuo de formação docente.

As mudanças no processo educacional, no contexto contemporâneo, decorrem da dinamicidade das tecnologias emergentes na sociedade, de modo que foram pertinentes as discussões sobre Educomunicação, uma vez que novas experiências têm provocado mudanças significativas na constituição e formação do sujeito contemporâneo e, consequentemente, no processo formativo do professor e práticas docentes em educação profissional.

No contexto contemporâneo, evidenciou-se a relevância da discussão sobre as práticas pedagógicas e a comunicação docente, diante dos desafios vivenciados ainda atualmente, que exigiram novas abordagens pedagógicas e diferentes habilidades, tanto para os educadores como para os educandos.

Revista Devir Educação, Lavras-MG. Edição Especial, p.53-70, Set./2021. 
A educação profissional se configura em um cenário em que se manifestam diferentes discursos e processos de identificação dos sujeitos e em que as exigências das tecnologias contemporâneas impõem desafios ao processo de ensino-aprendizagem que, por sua vez, envolve novas ações e metodologias, na produção do conhecimento e no saber-fazer educacional.

Ao se reiterar o saber-fazer, frente aos desafios e emergências, a atualização do docente incorpora fatos e significados que surgem com a experiência cotidiana na aplicação de pesquisas científicas sobre educação e estudos contemporâneos em comunicação, para se discutir a linguagem e as práticas pedagógicas em educação profissional. O discurso educacional, hoje, trata da importância do saber em uma sociedade, em que a realidade de como as novas tecnologias são tratadas na educação evidencia a necessidade de se pensar sobre mudanças no paradigma da produção e divulgação do conhecimento, bem como da necessidade da (res)significação dos saberes e comunicação docente.

É evidente a velocidade das transformações, decorrentes da imposição das novas tecnologias às mais variadas tarefas humanas, no trabalho e na educação e, por isso, não cede espaço para se explorar os acontecimentos com facilidade, apenas do ponto de vista perceptocognitivo. Nesse sentido, tudo se transforma aceleradamente, o que deixa clara a necessidade de se discutir os fins da educação contemporânea, em sintonia com essas novas tecnologias e a comunicação.

\section{Referências Bibliográficas}

ALVAREZ, S. M.; PRADOS, R. M. N. A emergente virtualização do ensino em 2020: considerações sobre inovação e tecnologias na educação profissional. Revista Diálogos em Educação, v. 1, n. 2, p. 86-97, jul./dez. 2020. DOI: https://doi.org/10.29327/227628.1.2-8.

APARICI, R.; OSUNA, S. Educomunicação e cultura digital. In: APARICI, R. (Org.). Educomunicação: para além do 2.0. São Paulo: Paulinas editora, 2014.

BASSIT, A. Z. O interdisciplinar - reflexões contemporâneas. São Paulo: Factash, 2010.

BRASIL. Agência Brasil explica: o que é o Sistema S. Agência Brasil. Rio de Janeiro, 21/09/2020. Disponível em: https://agenciabrasil.ebc.com.br/economia/noticia/202009/agencia-brasil-explica-o-que-e-o-sistema-s. Acesso em: 23 ago. 2021. 
CORACINI, M. J. Língua Estrangeira e Língua Materna. Uma questão de sujeito e identidade. In: Identidade e Discurso. CORACINI, M. J. (Org.). Campinas: Editora da UNICAMP Chapecó: Argos Editora Universitária, 2003.

FONTANILLE, J. Semiótica do Discurso. São Paulo: Contexto, 2008.

GARIGLIO, J. A.; BURNIER, S. Saberes da docência na Educação Profissional e Tecnológica: um estudo sobre o olhar dos professores. Educação em Revista, v. 28, n. 01, p. 211-236, 2012. DOI: https://doi.org/10.1590/S0102-46982012000100010.

GATTI, B. A.; BARRETto, E. S. S., ANDrÉ, M. E. D. A., AlMEIDA, P. C. A. Professores do Brasil: Novos Cenários de Formação. Brasília: UNESCO, 2019.

GÓMEZ, G. O. Entre telas: novos papéis comunicativos dos cidadãos. In: APARICI, R. (Org.). Educomunicação: para além do 2.0. São Paulo: Paulinas editora, 2014.

GREIMAS, A. J. Del Sentido II. Ensaios semioticos. Madrid: Gredos, 2001.

KAPLÚN, M. Uma pedagogia da Comunicação. In: APARICI, R. (Org.). Educomunicação: para além do 2.0. São Paulo: Paulinas editora, 2014.

MAINGUENEAU, D. Cenas da Enunciação. São Paulo: Parábola Editora, 2008.

MOURA, A. A educação ubíqua na era digital móvel: reconfiguração dos espaços de aprendizagem. In: BONINI, L. M. M.; SARTORELLO, R.; SCABBIA, R. J. A. (Orgs.). Dinâmicas Sociais e Desenvolvimento Local. Curitiba: CVR, 2017.

PAIS, C. T. Considerações sobre a semiótica das culturas, uma ciência da interpretação: inserção cultural, transcodificações transculturais. Revista Acta Semiótica et Lingvistica. SBPL, v. 11, a. 30, p. 149-157, 2007.

PETEROSSI; H. G. Subsídios ao estudo da Educação Profissional e Tecnológica. São Paulo: Centro Paula Souza, 2014.

PETEROSSI, H. G.; MENINO, S. E. A formação do formador. São Paulo: Centro Paula Souza, 2017.

PRADOS, R. M. N. Comunicação, Discurso pedagógico e formação docente em educação profissional. Revista de Estudos de Gestão, Informação e Tecnologias, v. 13, n. 1, p. 134146, jan./jun. 2020. Disponível em: http://www.revista.fatecitaqua.edu.br/index.php/regit/article/view/REGIT13-A10. Acesso em: 22 maio 2021.

PRADOS, R. M. N.; BONINI, L. M. M. Ensaios de Semiótica Aplicada. Curitiba: Editora CRV, 2017.

PRADOS, R. M. N.; RAMIREZ, R. A.; FERNANDEZ, S. A. F. Discursos e Práticas educacionais em Educação Profissional. Caminhos em Linguística Aplicada, v. 22, n. 1, p. 
213-226,

jan./jun.

2020.

Disponível

em:

http://periodicos.unitau.br/ojs/index.php/caminhoslinguistica/article/view/2913. Acesso em: 14 mar. 2021.

SOARES, S. G. Educação e comunicação. O ideal de inclusão pelas tecnologias de informação. Otimismo exacerbado e lucidez pedagógica. São Paulo: Cortez, 2006.

TARDIF, M. Saberes docentes e formação profissional. Petrópolis: Vozes, 2014.

Recebido em 18/06/21

Aprovado em: 25/08/21

Revista Devir Educação, Lavras-MG. Edição Especial, p.53-70, Set./2021. 